\title{
Temporal de levante en Baleares, la Comunidad Va- lenciana, Murcia y Almería (Dic-2016)
}

José MANuel LóPez PÉREZ y José Ángel NúÑEz MorA

Delegación territorial (DT) en Valencia, Agencia Estatal de Meteorología (AEMET)

\author{
Al meu país la pluja no sap ploure: \\ o plou poc o plou massa; \\ si plou poc és la sequera, \\ si plou massa és la catàstrofe.
}

Al meu país la pluja, lletra i música, 1983 - RAIMON

Este es el primero de los dos grandes temporales que se produjeron entre diciembre de 2016 y enero de 2017 en el litoral mediterráneo español. Este episodio afectó a Baleares, la Comunidad Valenciana y Murcia además de la provincia de Almería. Si bien los temporales de levante no son infrecuentes en estas zonas, lo que es menos habitual es la presencia de dos episodios en un período tan corto de tiempo, la época tan tardía (ambos en el invierno meteorológico) y la larga duración de los episodios, con dos fases claramente diferenciadas en ambos. Durante estos días se produjeron precipitaciones generalizadas, muy abundantes, con intensidades moderadas, aunque puntualmente llegaron a ser fuertes o muy fuertes en los momentos más activos del temporal. Las lluvias fueron persistentes en el tiempo y dieron lugar a totales acumulados de precipitación muy importantes (entre la mitad y el total del valor climatológico anual de las precipitaciones en esas zonas). Además y, como corresponde a todo temporal de levante, hubo vientos muy fuertes que dieron lugar a un fuerte oleaje con olas que superaron los 4 metros en gran parte del litoral y ocasionaron daños en la costa.

Palabras clave: sistemas de predicción por conjuntos aplicados a la predicción de corto y medio plazo, predicción probabilista, temporal de levante en el área mediterránea diciembre 2016.

Imagen parte superior: vista del macizo del Montgó, Denia (visto desde Oliva) en la comarca de la Marina Alta, al norte de la provincia de Alicante, el sábado 17 de diciembre de 2016 a las 14 horas. Fotografía de José ÁngEl NúÑEz MoRA. 


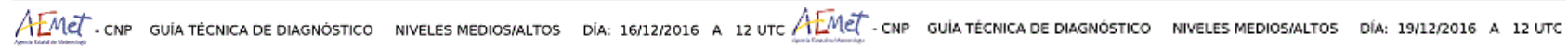

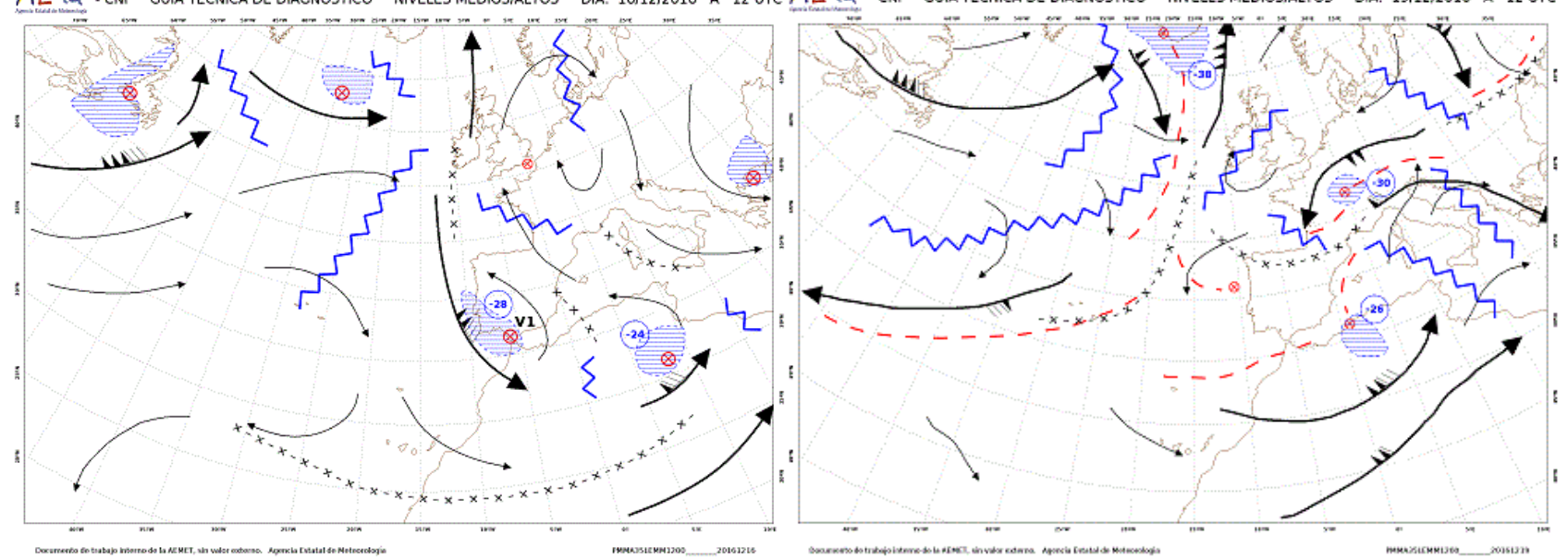

Figura 50.1: Guías técnicas de diagnóstico de niveles medio-altos del 16 de diciembre (izquierda) y 19 de diciembre (derecha), ambas a las 12 UTC. Izquierda: vaguada V1 con máximos de viento de 100 kt y anomalía fría de $-28^{\circ} \mathrm{C}$ en 500 hPa sobre el sur de Portugal y Andalucía occidental. Derecha: anomalía fría de $-26{ }^{\circ} \mathrm{C}$ en en 500 hPa sobre Argelia.

\subsection{Origen del temporal}

En niveles medio-altos de la troposfera el episodio se inicia con la aproximación por el oeste peninsular y en dirección norte-sur de una vaguada muy profunda con una anomalía de temperatura de $-28{ }^{\circ} \mathrm{C}$ en $500 \mathrm{hPa}$ y con un máximo de viento posterior de $130 \mathrm{kt}$ en 300 hPa (ver Figura 50.1).

La vaguada origina una formación de bajas presiones en superficie (Figura 50.2), primero en Andalucía y el estrecho de Gibraltar, para acabar focalizándose a sotavento del Atlas, en el sur de Marruecos, con 1014 hPa de presión en superficie a las 00 UTC del día 17.

En Gran Bretaña y Centroeuropa las altas presiones relativas en superficie se refuerzan hasta los 1038 $\mathrm{hPa}$, y se mantienen sin cambios significativos durante todo el temporal, mientras que la baja situada en Marruecos se profundiza ligeramente hasta $1012 \mathrm{hPa}$, y posteriormente se desplaza hacia el nordeste para profundizarse finalmente hasta $1004 \mathrm{hPa}$ y situarse finalmente sobre Baleares (Figura 50.3 en la página siguiente).
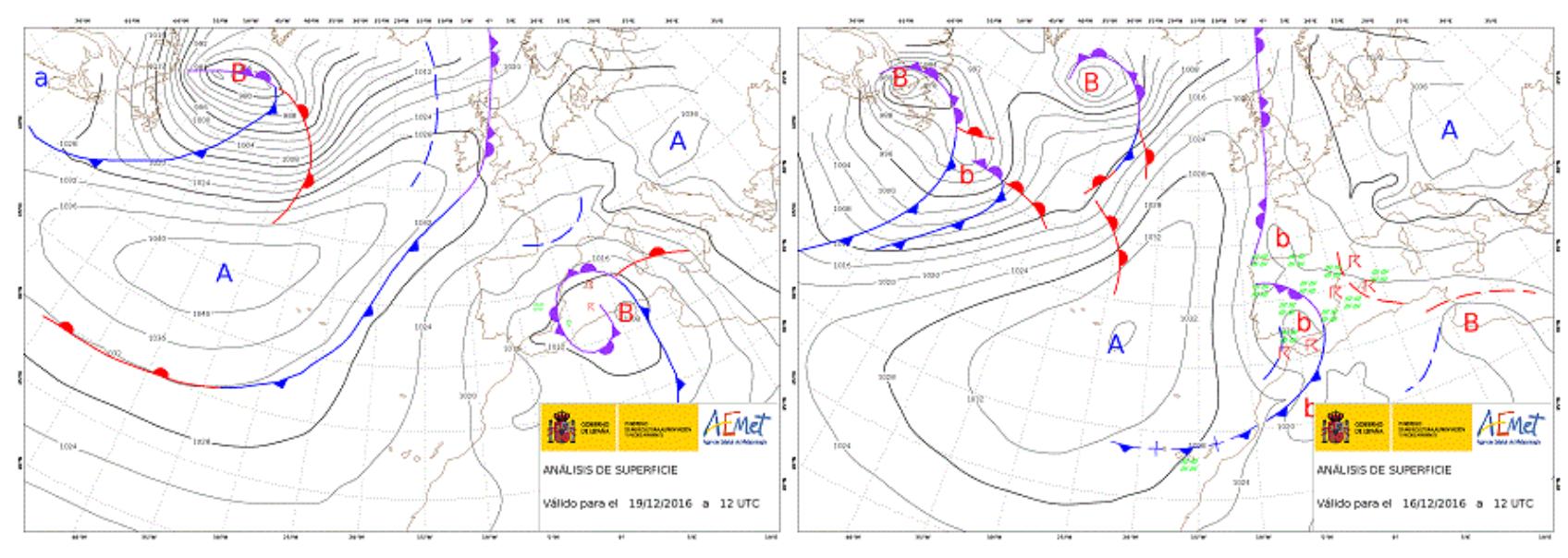

Figura 50.2: Izquierda: análisis de superficie del 16 de diciembre a las 12 UTC, donde destacan el anticiclón de Azores y el de Centroeuropa con un frente frío sobre desplazándose sobre Andalucía y Marruecos. Derecha: análisis de superficie del 19 de diciembre a las 12 UTC con la baja situada sobre Argelia y restos del frente ya ocluido sobre las costas de Valencia y Murcia. 

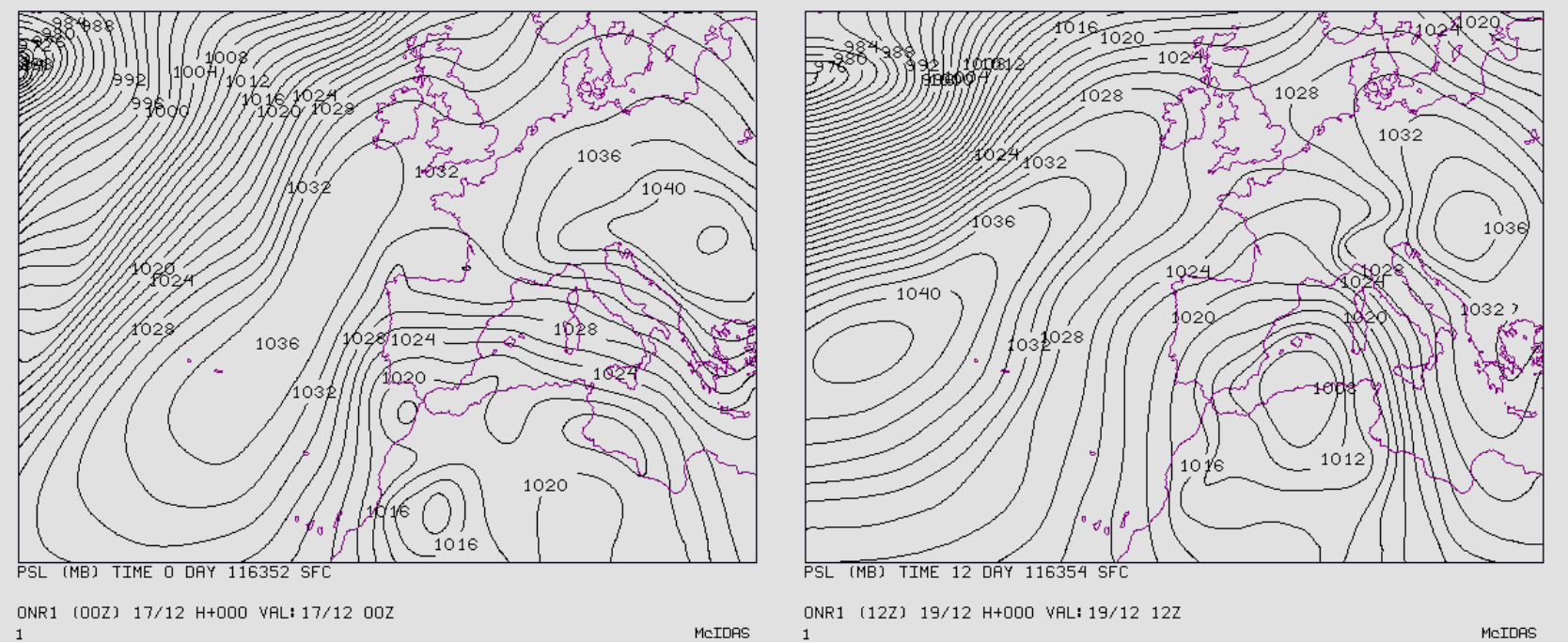

Figura 50.3: Análisis de presión en superficie para el 16-12-2016 a 12 UTC (izquierda) y para el día 19-12-2016 a 12 UTC (derecha).

Entre estos dos centros de acción se canalizó un flujo de componente este, con recorrido marítimo a lo largo de todo el mar Mediterráneo, a partir de la tarde del viernes 16 y hasta el final del episodio, 5 días más tarde. Este flujo de levante, con más de $3000 \mathrm{~km}$ de recorrido sobre el mar, permitió un gran aporte de humedad, desarrollándose las precipitaciones más intensas en las zonas en las que incidía (Figura 50.4).

Este flujo de humedad se desarrolló en dos fases diferenciadas: inicialmente, el viernes 16 incidió sobre
Baleares y el sur de la provincia de Castellón, desplazándose hacia el sur de la Comunidad Valenciana, Murcia y la provincia de Almería durante el sábado 17; a partir del domingo 18 y durante el lunes 19 , en la segunda fase, la más adversa del temporal, realizó el mismo recorrido pero en sentido inverso. En el extremo meridional de la zona afectada hay un único episodio de precipitaciones mientras que en la Comunidad Valenciana hay dos separados por 24 horas, entre las dos fases.

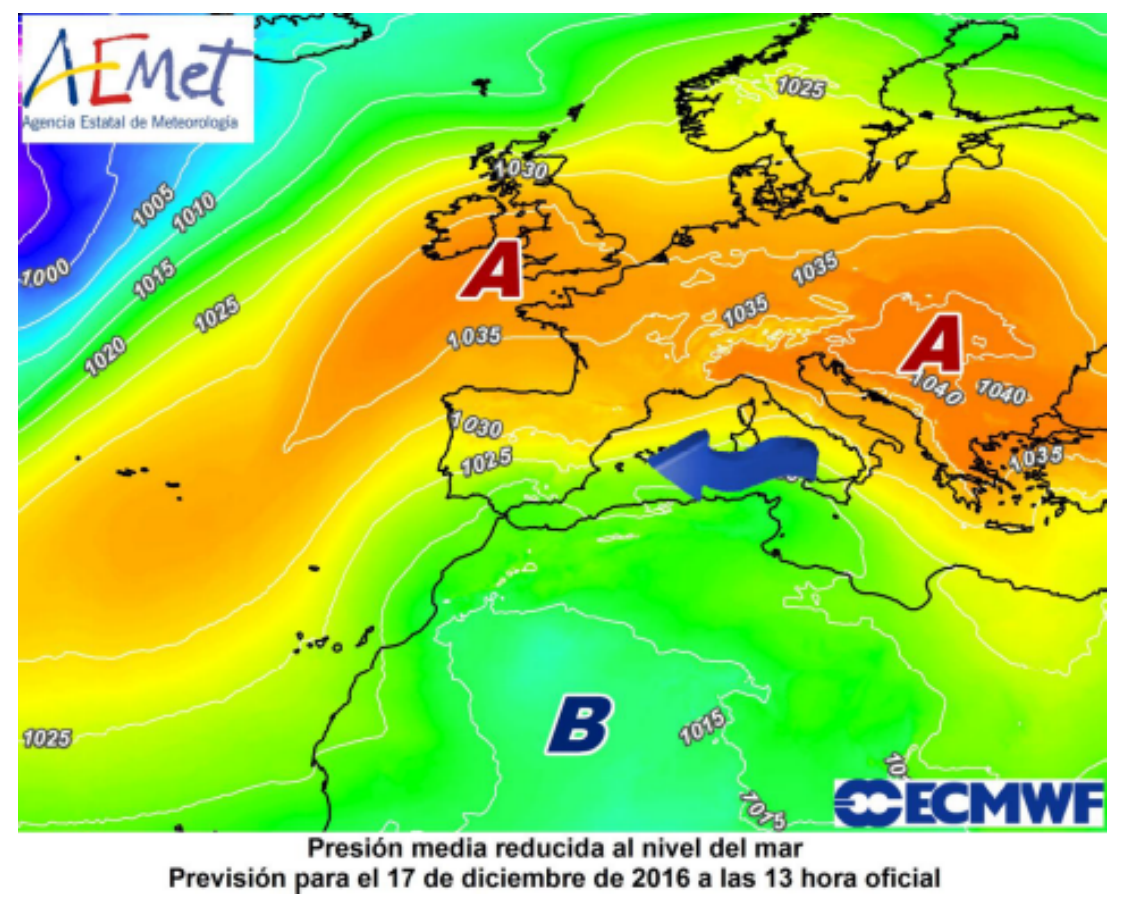

Figura 50.4: Modelo determinista del Centro Europeo de Predicción a Medio Plazo (ECHRES, sec. 19.2 en la página 291). Presión reducida al nivel del mar prevista para el 17 de diciembre a las 12 UTC. 
Las imágenes infrarrojas contienen información importante sobre las nubes, pero ofrecen pocos indicios sobre el contenido de vapor de agua. Las de vapor de agua indican el contenido de vapor de agua de niveles medio-altos de la troposfera y no nos ayudan a determinar la cantidad de precipitación que puede acumularse en tierra al no dar información sobre contenido de humedad en niveles bajos.

Los instrumentos de microondas a bordo de los satélites polares permiten generar imágenes del contenido total de agua en columna (TPW, sec. 7.5.2 en la página 98). Este representa la profundidad del agua líquida que se acumularía si todo el vapor de agua contenido en un cilindro hipotético ubicado sobre un determina- do lugar de la Tierra se condensara.

El laboratorio de investigación del sistema Tierra (Earth System Research Laboratory, ESRL) de la National Oceanic and Atmospheric Administration (NOAA) define los ríos atmosféricos como estrechas bandas atmosféricas responsables de la mayor parte del transporte de humedad desde las regiones tropicales hacia los polos. En los productos TPW estas bandas son visibles como franjas de valores elevados.

En las Figuras 50.5 y 50.6 en la página siguiente, se ve el balanceo del río de humedad entre los días 16 al 18 de diciembre de 2016, con sus dos fases bien marcadas, de norte a sur y de sur a norte.
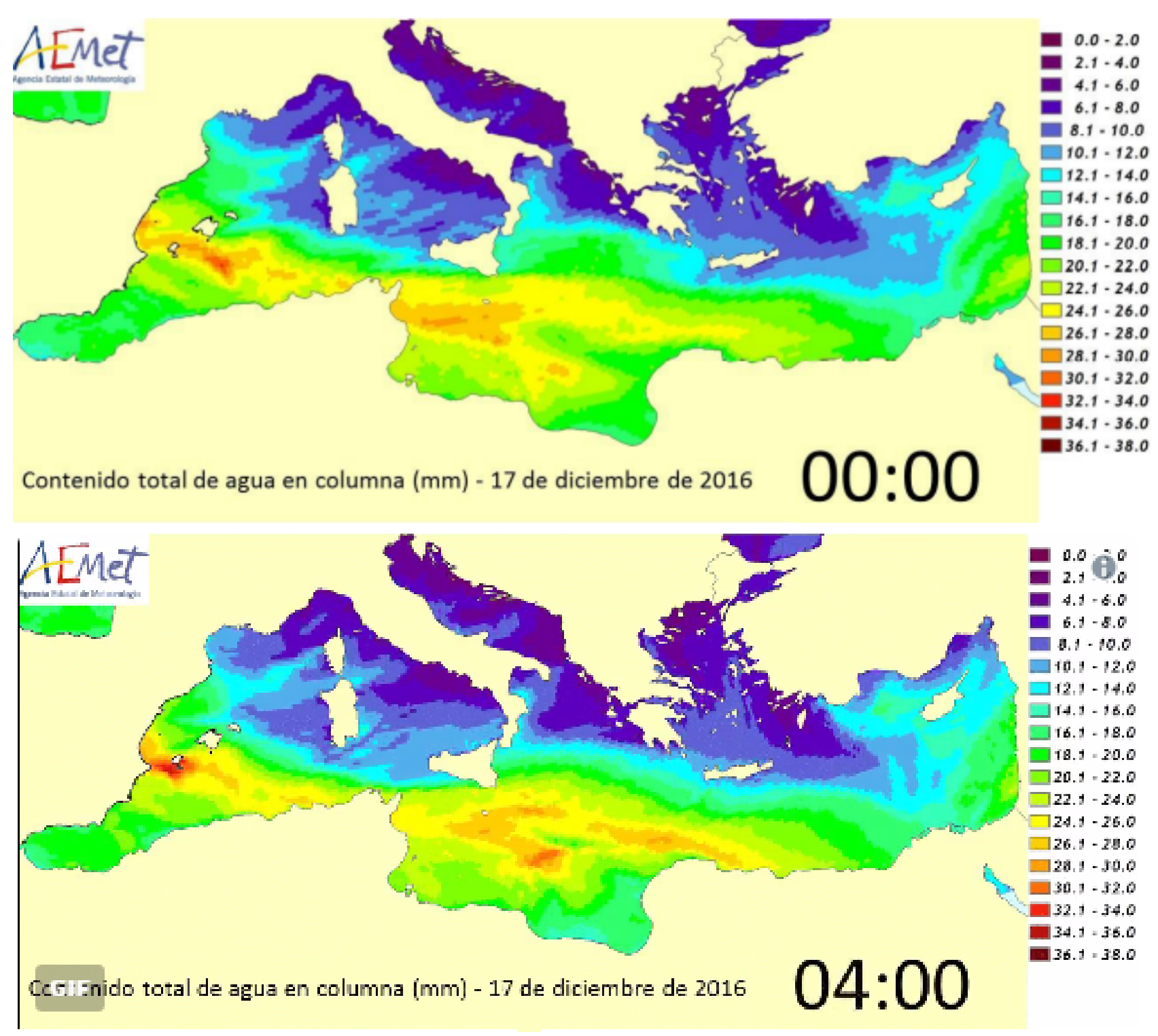

Figura 50.5: Contenido total de agua precipitable en la columna (TPW) de la troposfera para el 17 de diciembre a las 00 (arriba) y a las 04 (abajo), hora oficial peninsular. Agencia Estatal de Meteorología (AEMET). 


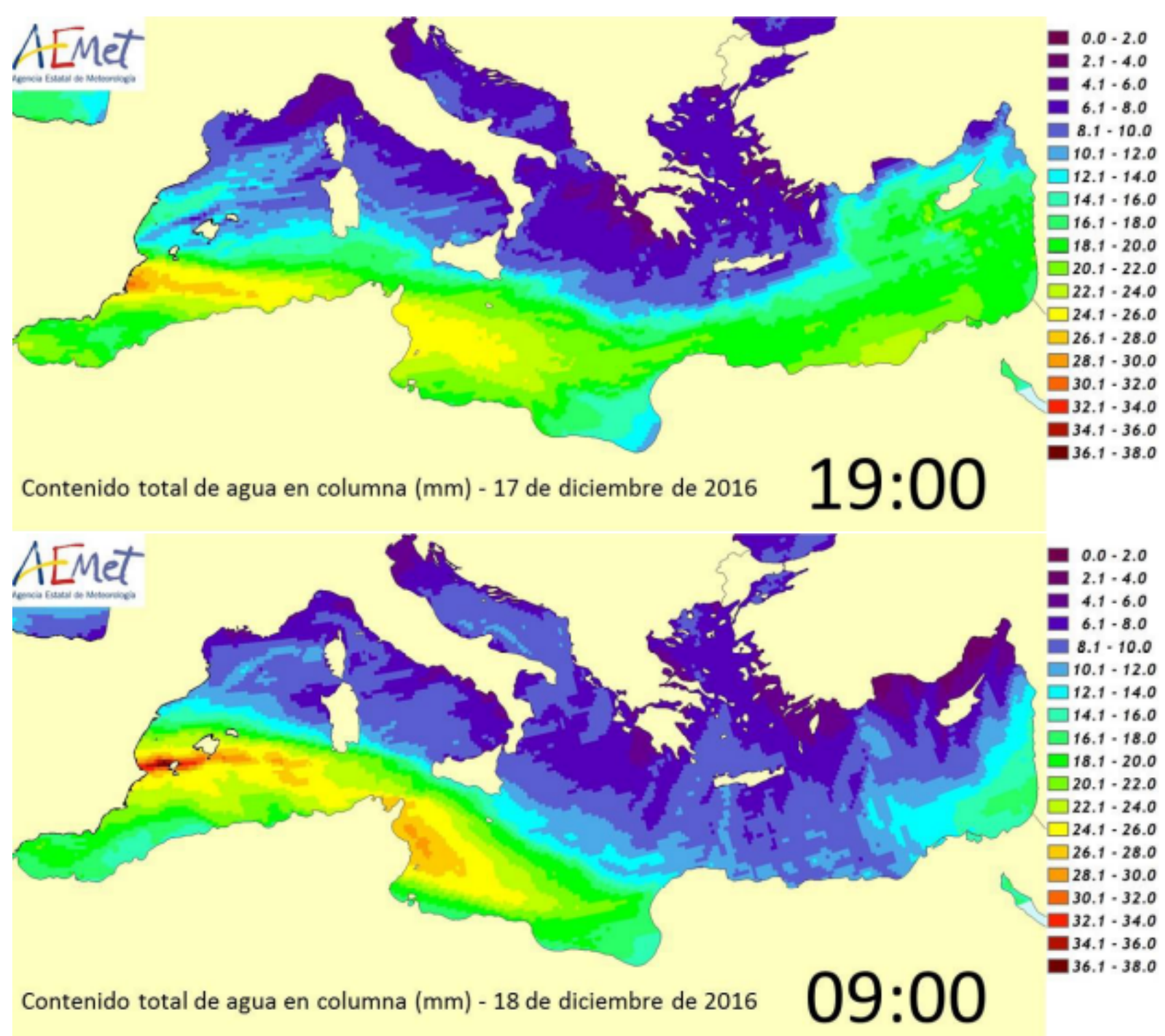

Figura 50.6: Contenido total de agua precipitable en la columna (TPW) de la troposfera para el 17 de diciembre a las 19 (arriba) y el día 18 a las 09 (abajo), hora oficial peninsular. AEMET.

Un temporal en estas fechas tan avanzadas del año, ya casi en invierno, requiere un chorro de viento en capas bajas, es decir, un flujo de aire muy intenso en la baja troposfera. Mientras que en septiembre y a principios de octubre puede haber grandes lluvias simplemente con la inestabilidad termodinámica atmosférica, sin apenas viento, en fecha tan avanzada del año, el viento que canalice las precipitaciones hacia las montañas litorales y prelitorales es necesario.

En la Figura 50.7 en la página siguiente [1] se puede ver el flujo de viento muy fuerte en la madrugada del día 19, cuando las precipitaciones en las sierras del norte de Alicante y sur de Valencia estaban siendo fuertes a muy fuertes y persistentes.

Por eso además de las lluvias, otro fenómeno desta- cado fue el viento. Las rachas más fuertes de viento durante el temporal en la Comunidad Valenciana se presentan en la Tabla 50.1.

\begin{tabular}{cc}
\hline Observatorio & Racha máxima $[\mathbf{k m} / \mathbf{h}]$ \\
\hline Barx & 96 \\
Polinyà & 75 \\
Aeropuerto Alicante & 74 \\
Jávea / Xàbia & 74 \\
Xàtiva & 73 \\
Oliva & 72 \\
Rojales & 71 \\
Carcaixent & 70 \\
\hline
\end{tabular}

Tabla 50.1: Rachas más intensas de viento durante el temporal de levante en la Comunidad Valenciana. 


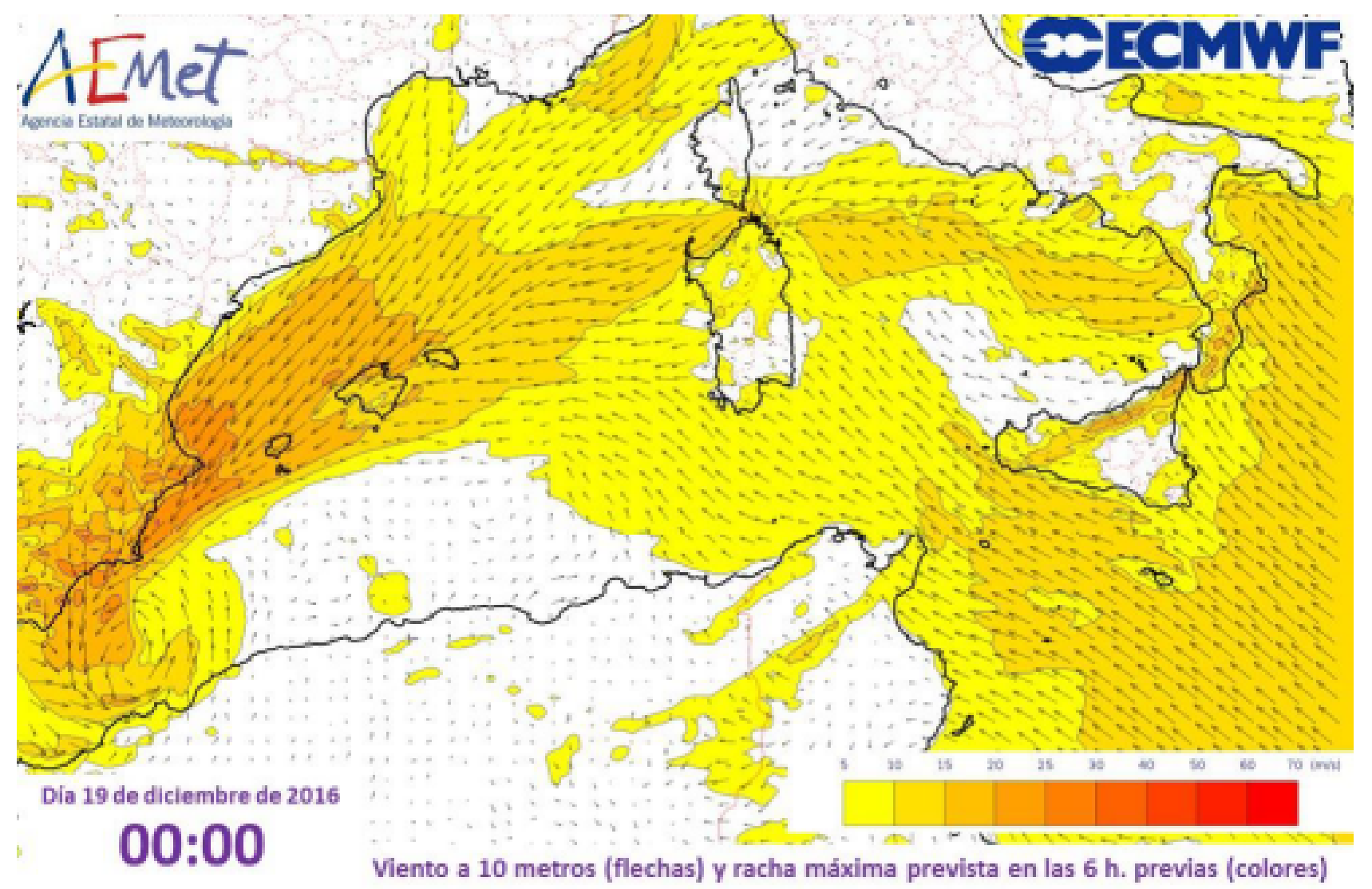

Figura 50.7: Predicción del modelo ECHRES para el 19 de diciembre a las 00 UTC del viento a 10 metros (flechas) y el valor de la racha máxima en las 6 horas previas (colores).

Como consecuencia del fuerte viento, la mar estuvo muy alterada, con olas que llegaron tener una altura de 4.4 metros en el puerto de Valencia y a 4.3 en el de Alicante.

\subsection{Descripción de las precipita- ciones del episodio}

Pero lo más destacado del temporal fueron las precipitaciones, de forma que se puede encuadrar al temporal de diciembre de 2016 como uno de los grandes temporales de levante históricos en la Comunidad Valenciana por el volumen de precipitación registrado, similar a otros grandes temporales registrados en fecha más temprana del otoño.

Los máximos acumulados se han registrado en la montaña del sur de Valencia y norte de Alicante, donde en el episodio se han superado los $400 \mathrm{~mm}$ en algunas localidades, y, lógicamente, cuando los máximos de precipitación se registran en zonas de montaña, surgen los problemas derivados de crecidas de ríos, ramblas, etc.

La característica más importante del temporal fue la persistencia. De los datos disponibles, en ninguna estación de la red la intensidad ha sido torrencial. Puntualmente la intensidad fue muy fuerte, con acumulados de entre $30 \mathrm{~mm}$ y $60 \mathrm{~mm}$ en menos de una hora, a última hora del domingo 18 , y en la madrugada del lunes 19, en estaciones del sur de Valencia y norte de Alicante.

La Tabla 50.2 en la página siguiente muestra precipitación acumulada en el episodio, entre el 16 y el 19 de diciembre de 2016 (día pluviométrico 07 a 07 UTC), en estaciones de la red de AEMET y de la Confederación Hidrográfica del Júcar. La Figura 50.8 en la página siguiente muestra mapas de precipitación acumulada registrada en el episodio, por un lado en la Península y Baleares y, por otro, ampliando detalle en la Comunidad Valenciana. 


\begin{tabular}{|c|c|c|c|c|c|}
\hline Localidad & Total & Localidad & Total & Localidad & Total \\
\hline Beniarrés & 433.2 & Alfondeguilla & 212.4 & Miramar & 130.0 \\
\hline Pinet & 398.6 & Càrcer & 210.6 & Valencia & 128.3 \\
\hline Orba & 379.7 & Guadalest & 209.8 & Rojales & 122.4 \\
\hline Barx & 365.4 & Villalonga & 209.0 & Almenara & 120.1 \\
\hline Millena & 356.0 & Pilar de la Horadada & 208.0 & Sagunt & 116.0 \\
\hline Vall de Laguart & 332.8 & Chiva & 207.0 & Benidorm & 111.2 \\
\hline Murla & 330.0 & Cortes de Pallás & 203.8 & Pinoso & 87.2 \\
\hline Muro de Alcoi & 322.8 & Teresa de Cofrentes & 201.6 & Alicante & 83.8 \\
\hline Agres & 304.6 & Chera & 200.6 & Elche & 80.4 \\
\hline Ontinyent & 289.2 & Alcoi & 197.2 & Segorbe & 80.2 \\
\hline Moixent & 271.2 & Vva. de Castellón & 196.0 & Castellón & 78.0 \\
\hline L'Adsubia & 263.4 & Bellús & 195.8 & Villena & 75.4 \\
\hline Vall de Gallinera & 263.0 & Navarrés & 185.6 & Chelva & 74.0 \\
\hline Navalón & 261.6 & Picassent & 172.6 & A. Alicante/Elche & 73.1 \\
\hline Enguera & 257.4 & Pego & 170.8 & Vilafranca & 72.4 \\
\hline Vallada & 255.0 & Picanya & 170.5 & Castellfort & 66.3 \\
\hline Buñol & 253.4 & Tous & 168.0 & Novelda & 64.6 \\
\hline Antella & 253.0 & Real de Montroy & 167.4 & Torreblanca & 61.6 \\
\hline Estubeny & 239.8 & Bicorp & 163.8 & Montanejos & 51.4 \\
\hline Carcaixent & 239.6 & Oliva & 154.1 & Utiel & 51.0 \\
\hline Bolbaite & 238.0 & Xàtiva & 152.8 & Atz. del Maestrat & 50.8 \\
\hline Siete Aguas & 233.2 & Torrevieja & 151.1 & Morella & 46.0 \\
\hline Alfondeguilla & 212.4 & Orihuela & 138.2 & Fredes & 28.2 \\
\hline
\end{tabular}

Tabla 50.2: Precipitación acumulada en el episodio, entre el 16 y el 19 de diciembre de 2016 (día pluviométrico 07 a 07 UTC), en estaciones seleccionadas de la red de AEMET y de la Confederación Hidrográfica del Júcar.
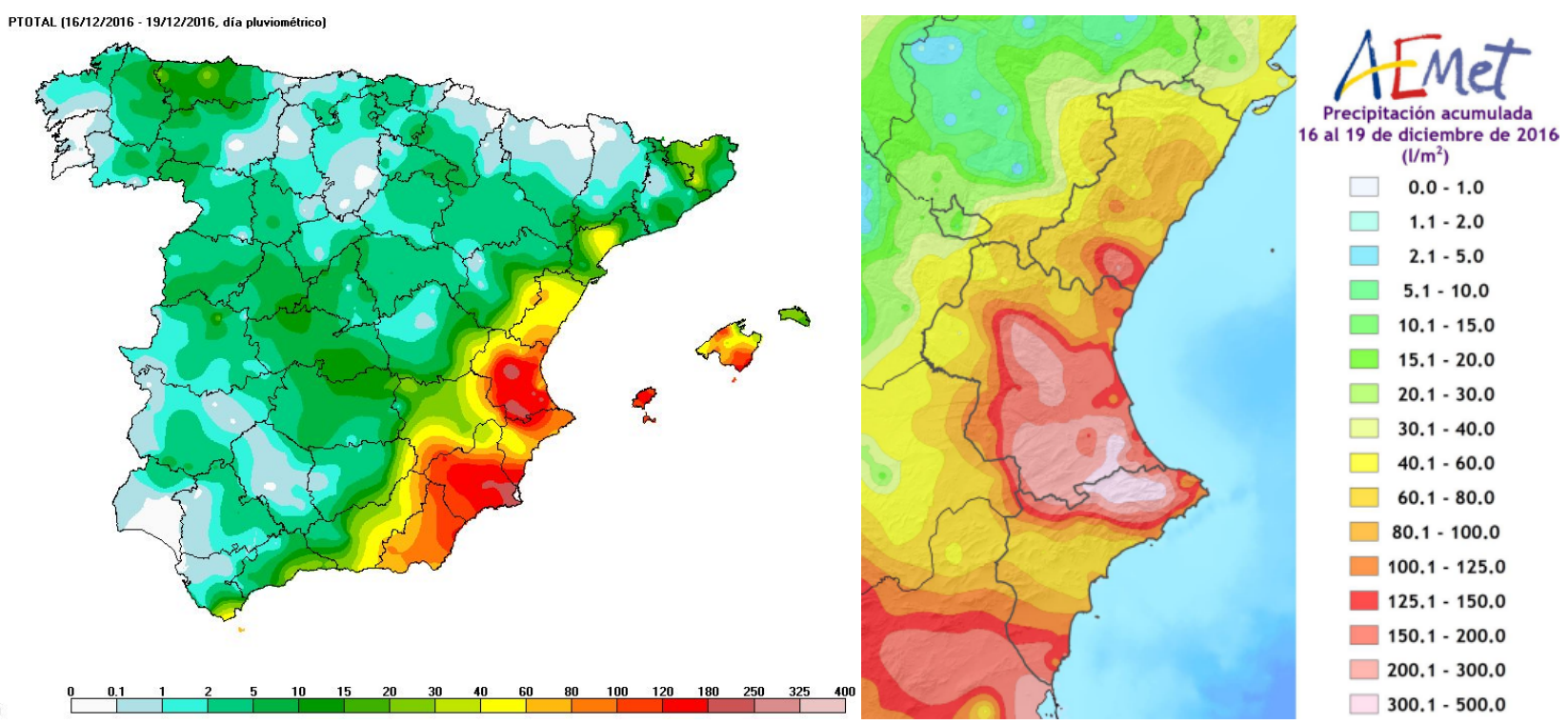

Figura 50.8: Precipitación en mm acumulada entre el 16 y el 19 de diciembre de 2016 (día pluviométrico, 07 a 07 UTC). Datos de las redes de AEMET y la Confederación Hidrográfica del Júcar. Izquierda: Península y Baleares. Derecha: detalle de la Comunidad Valenciana, con otra escala de colores. 


\section{EPS CEPPM 16 Dic. 2016 a 00 UTC Probabilidad precipitación acumulada de 00 a 24 UTC}
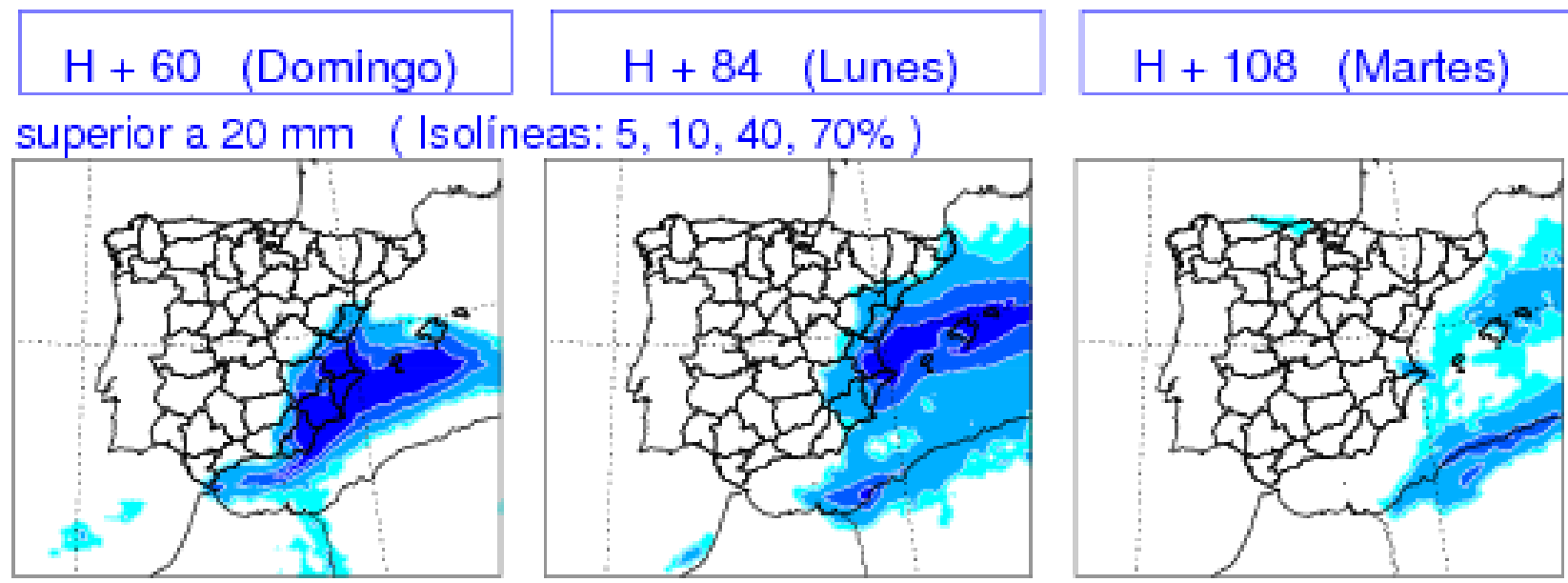

Figura 50.9: Probabilidad de precipitación acumulada superior a $20 \mathrm{~mm}$ según el SPC del ECMWF (ECENS, sec. 19.3 en la página 293), pasada de 16-12-2017 00 UTC. Isolíneas delimitando intervalos de probabilidad 5-10\% (cian), $10-40 \%$ (azul claro), 40-70\% (azul marino) y 70-100\% (azul oscuro).

\subsection{Predicciones probabilistas}

Mostramos dos salidas de las predicciones probabilistas del SPC del ECMWF, ECENS (sec. 19.3 en la página 293): probabilidad de que la precipitación prevista acumulada en 24 horas supere el umbral de los $20 \mathrm{~mm}$ para los días D+3, 4 y 5 y probabilidad de altura prevista de olas de mar de viento para los días $\mathrm{D}+2,3$ y 4 .

\subsubsection{Precipitación}

Analizaremos tres pasadas distintas: viernes 16 a las 00 UTC para el domingo 18 (D+3), lunes 19 (D+4) y martes $20(\mathrm{D}+5)$; Viernes 16 a las 12 UTC para el lunes $19(\mathrm{D}+3)$, martes $20(\mathrm{D}+4)$ y miércoles 21 (D+5) 1C Sábado 17 a las 00 UTC para el lunes 19 $(\mathrm{D}+3)$, martes $20(\mathrm{D}+4)$ y miércoles $21(\mathrm{D}+5)$.

Pasada de viernes 1600 UTC. Para el domingo 18, se puede observar una amplia zona con más de un $70 \%$ de probabilidad que abarca la isla de Ibiza y las provincias de Valencia, Alicante, Murcia y Almería oriental. El lunes 19 continuarían las precipitaciones desplazándose la zona con máxima probabilidad hacia el este, con un área de más del $70 \%$ de probabilidad afectando a las islas de Mallorca y Menorca y, en menor medida, a las provincias de Valencia y Alicante. Figura 50.9.

Pasada de viernes 1612 UTC. La predicción para el lunes 19 similar a la mostrada anteriormente para el mismo día. Para el martes hay cambios y aumenta la zona con una probabilidad mayor del $40 \%$ abarcando desde las islas hasta la costa catalana. Figura 50.10 en la página siguiente.

Pasada de sábado 1700 UTC. El área con mayor probabilidad se mantiene sin cambios centrada en Baleares, Valencia y Alicante para el lunes 19. Para el martes 20, confirma el desplazamiento de la precipitación hacia Cataluña. Para el miércoles 21 se prevé la finalización del temporal de precipitación. Figura 50.11 en la página siguiente.

En resumen, la predicción probabilista del ECENS del ECMWF para tres días $(\mathrm{D}+3 / \mathrm{H}+60)$ y para cuatro días $(\mathrm{D}+4 / \mathrm{H}+84)$ indica claramente las zonas y días en que se producirán las mayores precipitaciones: Murcia, norte de Alicante y sur de Valencia y las islas de Ibiza y Mallorca. 


\section{MAPAS DE PROBABILIDAD // Pasada: 16 Dic. 2016 a 12 UTC Precipitacion acumulada en 24 horas (de 0 a $24 \mathrm{Z}$ )}
$D+3$ (Lunes)
$D+4$ (Martes)
$D+5$ (Miercoles)

Precipitacion superior a $20 \mathrm{~mm}(5,10,40,70)$
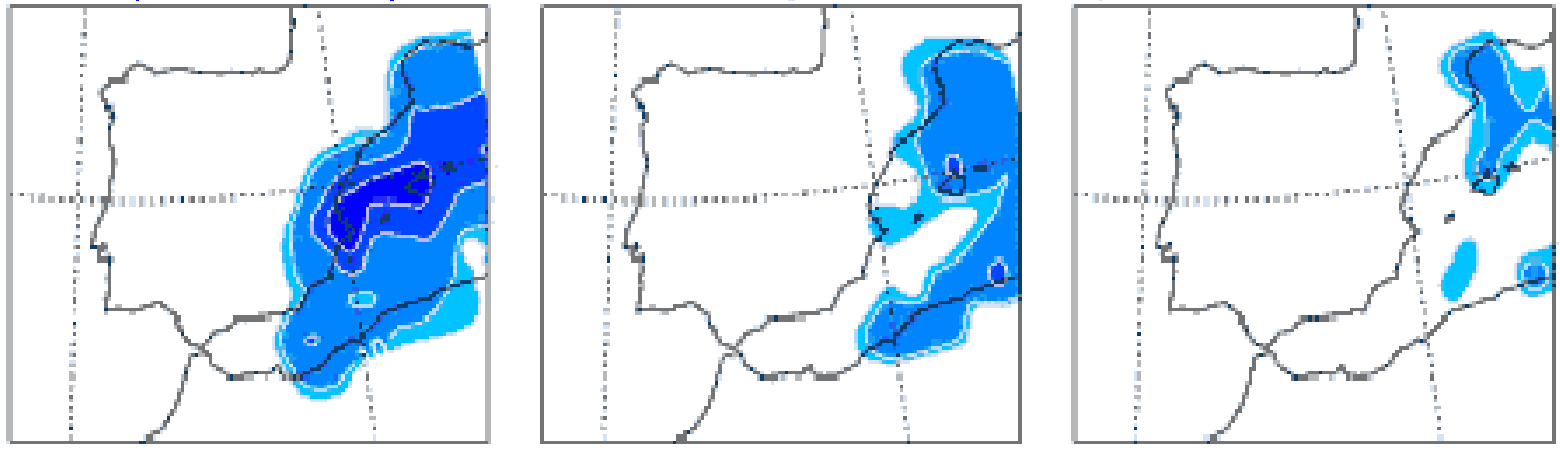

Figura 50.10: Pasada de 16-12-2017 12 UTC.
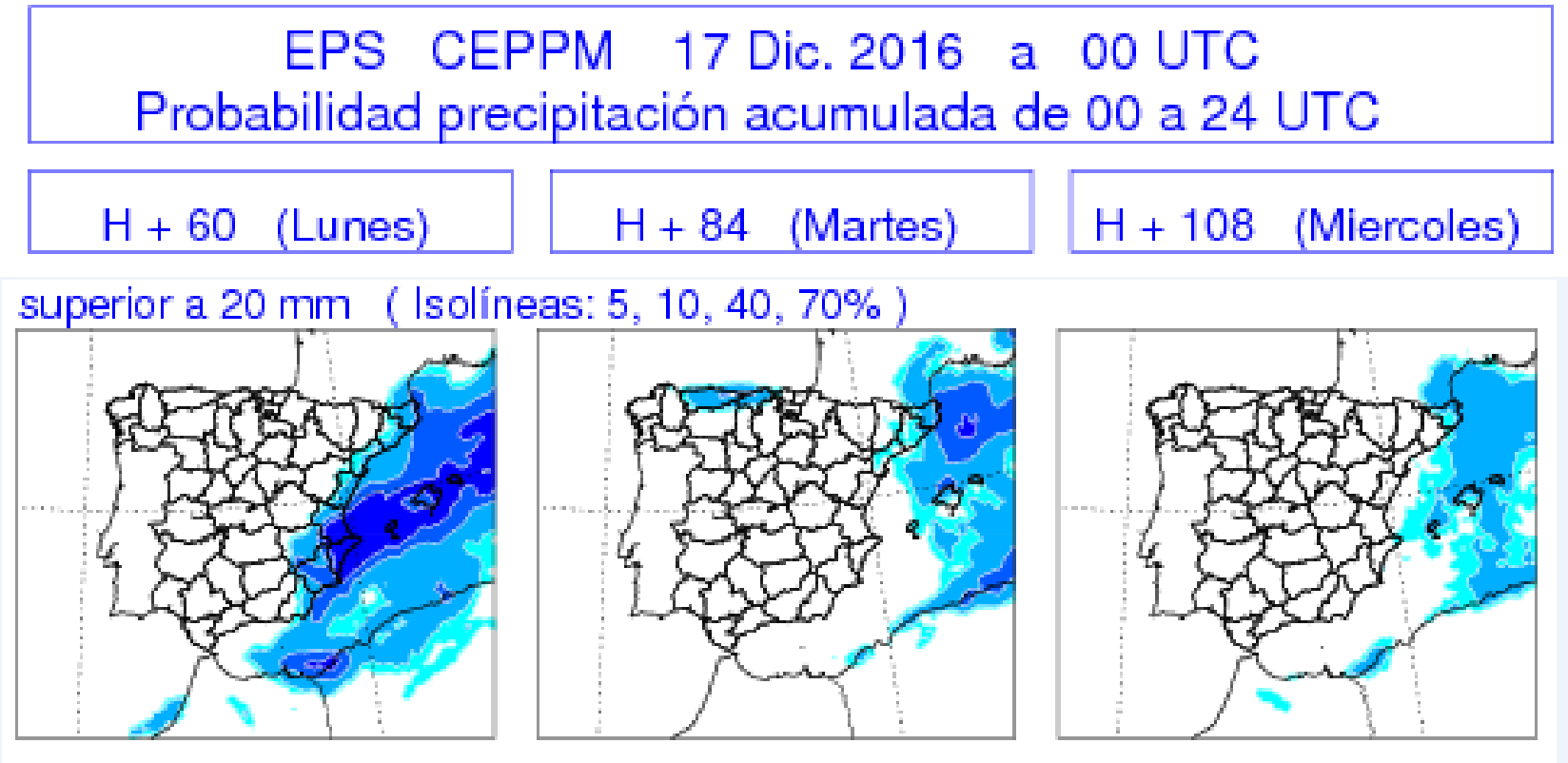

\section{$\mathrm{H}+108$ (Miercoles)}

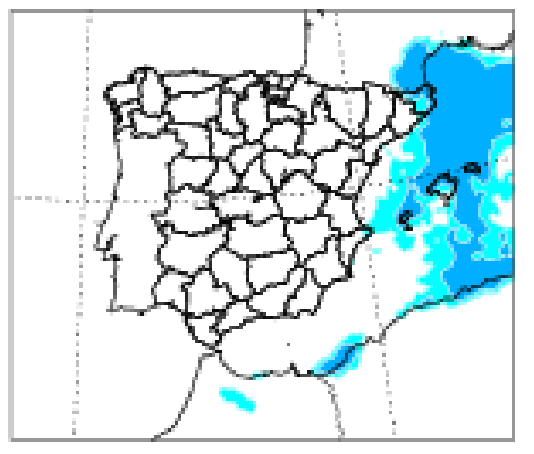

Figura 50.11: Pasada de 17-12-2017 00 UTC.

La Figura 50.12 en la página siguiente ofrece algo más de detalle geográfico. Muestra, igualmente, la predicción probabilista del ECENS de precipitación acumulada superior a $20 \mathrm{~mm}$ con mapas de mayor tamaño, todos correspondientes a la pasada de 16-12201712 UTC. Un mapa es válido para el domingo
18 a las 00 UTC (D+2), otro para el lunes 19 a las 00 UTC (D+3) y otro para el martes 20 a las 00 UTC $(\mathrm{D}+4)$. Pueden ratificarse los patrones de probabilidad de precipitación descritos anteriormente. La escala de probabilidad en estos mapas, situada a la derecha, abarca desde $2 \%$ (verde manzana) hasta $100 \%$ (rojo). 

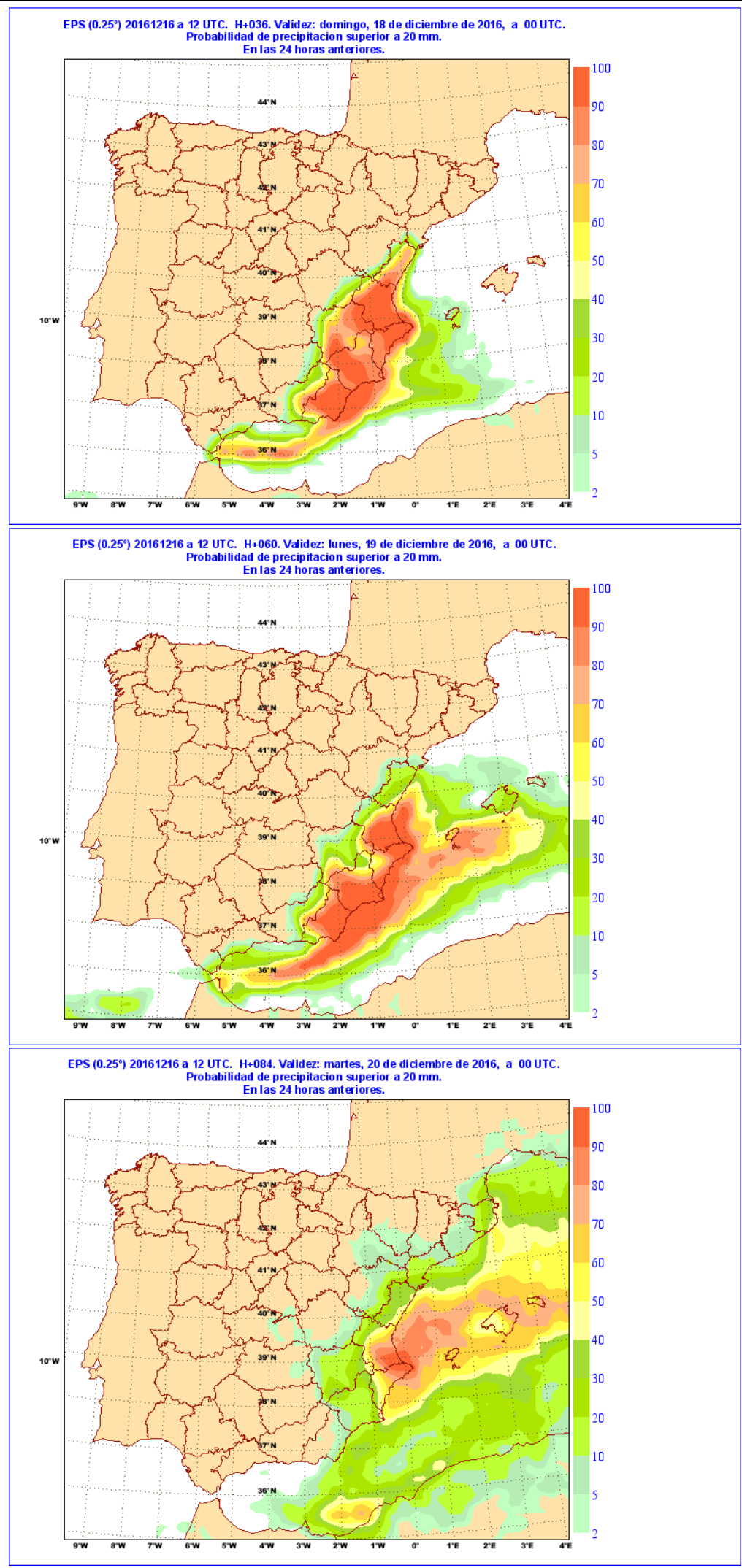

Figura 50.12: Predicción probabilista del ECENS de precipitación acumulada superior a 20 mm con algo más de detalle geográfico, pasada de 16-12-2017 12 UTC. Válida para el domingo 18 a las 00 UTC (D+2, superior), lunes 19 a las 00 UTC (D+3, centro) y martes 20 a las $00 \mathrm{UTC}(D+4$, inferior $)$. La escala de probabilidad, situada a la derecha de las figuras, abarca desde $2 \%$ (verde manzana) hasta $100 \%$ (rojo). 


\section{MAPAS DE PROBABILIDAD // Pasada: 16 Dic. 2016 a 00 UTC Altura de olas mar de viento}
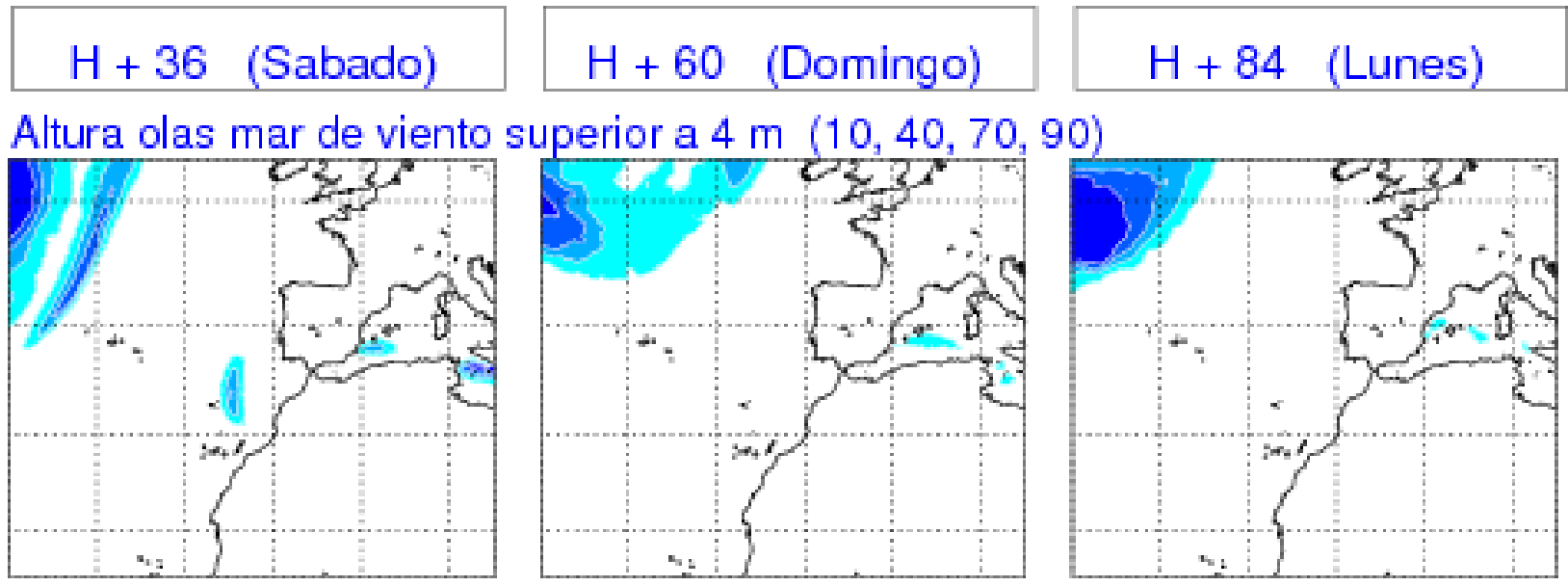

Tabla 50.3: Probabilidad de altura significativa de las olas superior a 4 m según el ECENS. Isolíneas delimitando intervalos de probabilidad de 5-10\% (cian), 10-40\% (azul claro), 40-70\% (azul marino) y 70-100\% (azul oscuro).

\subsubsection{Altura del oleaje}

La predicción probabilista de altura de olas por el mar de viento del 16 a las 00 UTC para D+2 (sábado), $\mathrm{D}+3$ (domingo) y D+4 (lunes). No hay previsión de altura de olas superior a $4 \mathrm{~m}$ en ninguna zona, excepto para el sábado que con una probabilidad mínima del $10 \%$ da una pequeña zona entre Ibiza y Alicante.

La predicción probabilista para el oleaje (también para el viento, ya que el oleaje es muy dependiente del viento, figuras no mostradas), se queda claramente por debajo de las olas observadas $(4,2-4,3 \mathrm{~m})$. La probabilidad de olas de más de $4 \mathrm{~m}$ a 36 horas vista es insignificante. Esto es así porque probablemente el modelo infravalora la profundidad de la ciclogénesis al no tener suficientemente en cuenta la contribución de la liberación de calor latente de condensación que se realiza en una escala espacio-temporal menor que la contribución dinámica.

\subsection{Conclusiones}

El temporal de los días 16 al 19 de diciembre fue muy adverso en el litoral mediterráneo de la Península, tanto en las precipitaciones como en el viento y, en la franja litoral, el oleaje. La Figura 50.13 en la página siguiente muestra imágenes de algunos de los impactos del episodio.
Además de las causas de la génesis del temporal y su desarrollo, en este capítulo se han analizado productos de sistemas de predicción por conjuntos (SPC) procedentes del Centro Europeo de Predicción a Plazo Medio (ECMWF, cap. 19 en la página 289), ya que cuando existe la probabilidad de que en los próximos días se pueda desarrollar un temporal especialmente adverso, con serias consecuencias para las infraestructuras y cierto riesgo para la población, la cuantificación de esa probabilidad es una herramienta fundamental para orientar a las autoridades, a los responsables de protección civil y a la población en general.

La probabilidad de las precipitaciones acumuladas está bien prevista por los productos probabilistas del ECENS tanto en las áreas afectadas como el abanico temporal previsto. El umbral de $20 \mathrm{~mm}$ considerado es, en principio, demasiado bajo para la acumulación de precipitación que se da en este tipo de episodios, en los que pueden registrarse cantidades muy superiores. Ahora bien, dado que encontrar señal de un evento de estas características es buscar en la cola de la distribución climatológica, sabemos por experiencia que, aunque las señales sean débiles (probabilidades bajas) en umbrales aparentemente bajos (como $20 \mathrm{~mm}$ ), sí que pueden considerarse significativas.

Respecto al viento y el oleaje, la predicción probabilista no brinda probabilidades altas de superación de umbrales claramente inferiores a las intensidades 
o alturas registradas. No obstante y, por todo lo dicho anteriormente, podemos entender que, además de intervenir factores que el modelo no tiene suficientemente en cuenta, debemos tener en cuenta que el sistema(s) de predicción por conjuntos (SPC) ofrece señales tenues en umbrales relativamente altos que, si se interpretan adecuadamente, pueden ofrecer información muy valiosa.
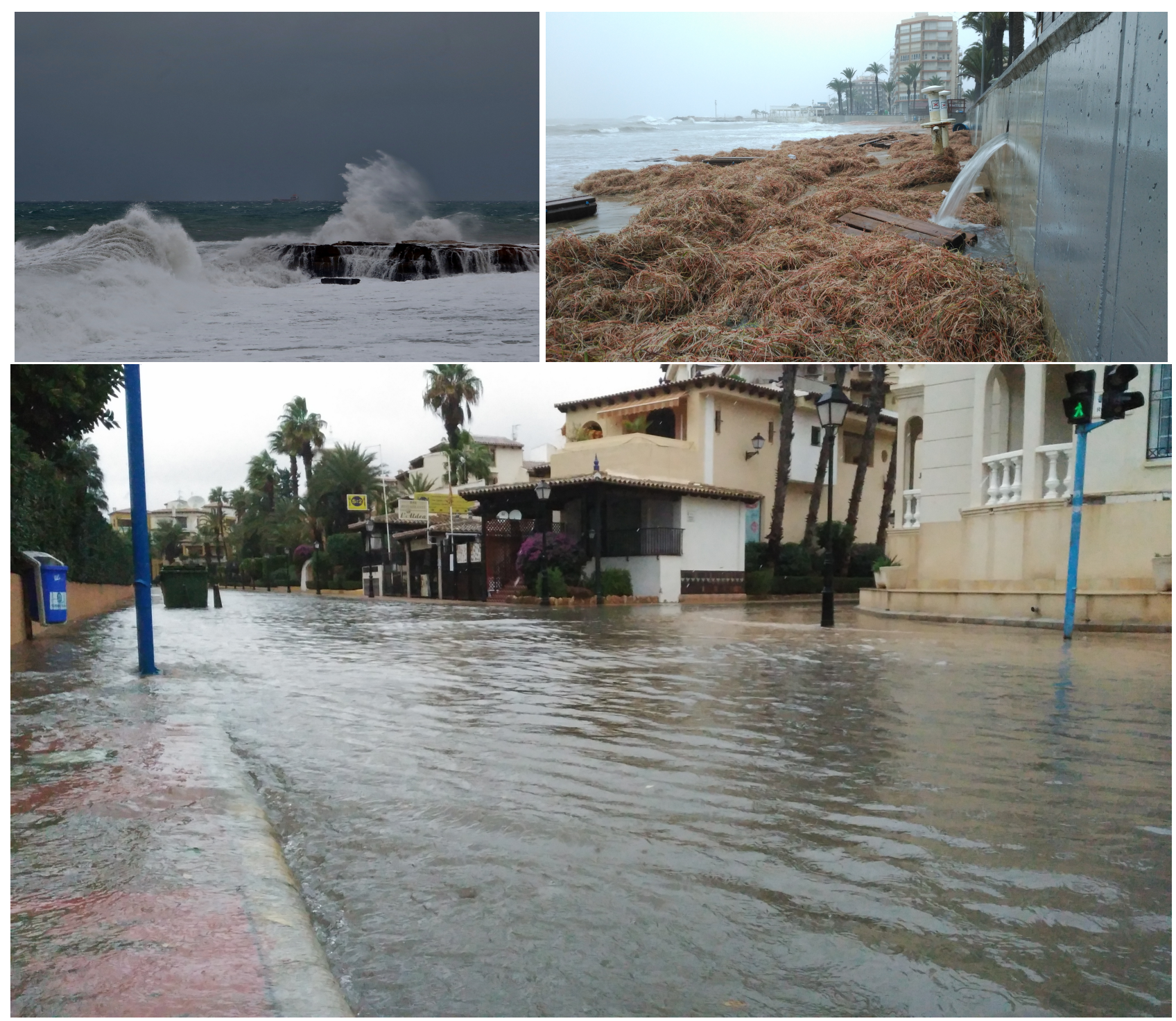

Figura 50.13: Arriba, izquierda: estado de la mar en el episodio del 18 de diciembre de 2016, fotografía de JOAQUíN CARRIÓN. Arriba, derecha: impactos producidos en Torrevieja, foto de RICARDO GRANADOS. Abajo: inundaciones en Torrevieja el 17 de diciembre de 2016, calle Roentgen, fotografía de RICARDO GRANADOs. Fotografías cedidas a través de Proyecto Mastral Torrevieja http: //www. eltiempoentorrevieja. es/. 


\subsection{Referencias}

[1] Persson, Anders. "User guide to ECMWF forecast products". En: Ecmwf March (2011), página 127 (citado en página 767). 